\title{
Etnocentrismo:
}

\author{
inconsciente, imaginário e preconceito \\ no universo das organizações educativas*
}

Para Jean Duvignaud.

José Carlos de Paula Carvalho

O etnocentrismo consiste em privilegiar um universo de representações propondo-o como modelo e reduzindo à insignificância os demais univer sos e culturas “diferentes". De fato, trata-se de uma violência que, historicamente, não só se concretizou por meio da violência física contida nas diversas formas de colonialismos, mas, sobretudo, disfarçadamente por meio daquilo que Pierre Bourdieu chama “violência simbólica", que é o “colonialismo cognitivo" na antropologia de De Martino. Privilegia-se um referencial teórico-prático que segue o "padrão da racionalidade técnica" (LéviStrauss), escolhendo-se, assim, o único tipo de cultura e educação com ele compatíveis (“cultura hegemônica" e "culturas subalternas"), declarando-se "outras" as culturas diferentes com orientações incompatíveis com o referencial escolhido; procura-se reduzi-las nas suas especificidades e diferenças tornando-as mais diferentes do que são e, a seguir, são exorcizadas, por meio de várias estratégias. Em profundidade está-se projetando "fora”, como Outro e como Sombra, o que é incompatível e perigoso reconhecer que pertença ao universo da cultura padrão escolhida. A educação e as organizações educativas são instrumentos culturais desse colonialismo cognitivo: é o etnocentrismo pedagógico e o correlato psico-cultural do "furor pedagógico", uma gestão escolar autoritária e impositiva para nivelar as diferenças das culturas grupais por meio do planejamento. $\mathrm{O}$

\footnotetext{
* Palestra proferida nos Seminários de Cultura, Escola e Cotidiano Escolar - FEUSP - 1996

${ }^{1}$ Professor Titular da Faculdade de Educação da Universidade de São Paulo - FEUSP.
} 
etnocentrismo consiste na dimensão ético-política da mesma problemática cuja dimensão psicoantropológica envolve a Sombra ou Inconsciente. Vejamos a primeira dimensão.

O etnocentrismo origina e tem origem na "heterofobia" (o Outro - em suas diversas formas: primitivo, selvagem, louco, imaturo, homossexual, "homens de cor", crianças problemáticas, fascistas, baderneiros, "hippies", "mulheres de vida fácil”, hereges etc. - constitui "perigo" que deve ser exterminado. Observação: o servidor público, nas estratégias de neoliberalismo, está dentro dessa dinâmica, mas, sobretudo, impregnado da problemática de uma Sombra do poder ...). Valendo-se da distinção de Lévi-Strauss entre dois tipos de sociedade, as que praticam a antropofagia (que vêem na absorção de certos indivíduos detentores de forças temíveis o único meio de neutralizá-las aproveitando-Ihes a energia) e as que praticam a antropoemia (que, diante do mesmo problema escolheram a solução de expulsar fora do corpo social e manter temporária ou definitivamente isolados, sem contato com a "humanidade", os seres e grupos temidos, trancafiados em "reservas territoriais"), P. A. Taguieff mostra que quatro são as estratégias do etnocentrismo geradoras das diversas formas de preconceito e racismo:

1 antropofagia dialógica: racização amena de englobar o Outro no e pelo discurso persuasivo, forma predominante, em educação, do "homo academicus" e de muitas pedagogias dialógicas; é fundamental, em forma estereotipada, na mídia política;

2 antropofagia digestiva: racização repressiva da assimilação dos outros a si mesmo, todas as formas de aculturação;

3 antropoemia genocida: racização terrorista da destruição dos outros, como no caso das perseguições aos judeus, armênios, ciganos, feiticeiras, linchamentos etc;

4 antropoemia da tolerância: racização específica do desenvolvimento "em separado": em aparência, respeita-se tanto o outro, tolerando-o, o que na realidade, acaba-se por isolá-lo, não se dando aos trabalhos dos enfrentamentos de diferenças, típico de todas as ideologias do relativismo e ecumenismo.

O filme de Herzog, “Onde Sonham as Formigas Verdes”, ilustra perfeitamente essa problemática da alteridade e como tratá-la, sob a forma do etnocentrismo, que é a dimensão ético-política da problemática da alteridade. Já o filme "Sem Destino", de Fonda, ilustra mais a dimensão psicoantropológica da problemática da alteridade, a questão da Sombra. Em culturanálise de grupos, os trabalhos de Maria Cândida Garcez de Oliveira e Maria I nês Joffre Tanus são estudos sobre o etnocentrismo como colonialismo cognitivo em escolas, respectivamente no caso de favelados e migrantes, que mostram as estratégias escolares de gestão desse imaginário "diferente" e as resistências, que acabam por criar organizações e educação paralelas e alternativas de grupos.

Vejamos a dimensão da Sombra. Por meio da produção do Outro, em profundidade, elude-se a emergência do Inconsciente pelo I maginário. A antropologia psicanalítica, desde Róheim até os desenvolvimentos da antropopsicanálise institucional de Anzieu e Kaës, sobretudo valendo-se dos 
estudos dos discípulos de M. Klein e daqueles em torno e a partir da obra de Jung (Círculo de Eranos, Escola de Grenoble etc.), mas também dos estudos da etnopsiquiatria cultural de Devereux, de grande importância para a escola, evidencia a existência de uma energética sócio-psico-grupal. Seguindo-se o “híbrido Klein-Jung” e a arquetipologia sócio-cultural da Escola de Grenoble, diríamos que a psique individual, grupal e coletiva representa a elaboração da libido em seus vários níveis, do patente ao latente, pelas organizações sociais. A cultura representa uma organização da libido em nível individual, grupal e coletivo, de modo que as organizações sociais, que são organizações educativas, são organizações da libido, e a educação é um trabalho libidinal. A dinâmica dessa organização é uma dinâmica de sublimação repressiva, de modo que o reprimido, sob a forma do latente, sempre ameaça retornar, invadindo, como Outro, a cultura patente ou instituída. Essa dinâmica desvenda as leis da energética sócio-psico-grupal, de que parte a culturanálise de grupos. Resumidamente, em termos de psique individual, grupal e coletiva dizemos que a lei da complementaridade significa que a libido é organizada no funcionamento de um apar elho psíquicogrupal envolvendo as dimensões do Consciente e do Inconsciente, desde a primeira tópica de Freud, a que Jung deu os nomes de Persona e Sombra. Entretanto, não é pelo fato dessa existência complementar, que existem, de modo equilibrado, individual, grupal e coletivamente, essas dimensões, seja devido à repressão que constrói seletivamente a sociedade e a cultura em suas instituições (Freud e Marcuse), seja devido também ao material arquetípico que não tem mais acesso à consciência (Jung). Por isso a lei da enantiodromia: toda vez que uma orientação de desenvolvimento libidinal se unidimensionaliza no indivíduo, grupo ou sociedade, em termos consciente ou patente, constela-se inconscientemente o oposto que explode como Outro, na dinâmica da produção do Outro, criando-se o mal-estar, o perigo. Se não há elaboração, não ocorre uma confrontação, havendo, portanto, projeção. E a lei da heterotelia mostra que jamais os indivíduos e as organizações educativas conseguirão atingir suas metas racionalmente propostas em suas culturas patentes, se não levarem em consideração o latente, que é o Outro que está dentro delas mesmas. Por isso que se diz dos efeitos inesperados ou "perversos" no universo da vida individual e coletiva: por desconhecimento da dimensão latente do inconsciente que se dá por meio das produções imaginárias e/ ou em virtude de uma recusa de levar em conta (elaboração), explode o resultado contrário do que se esperava. Isso é endêmico no universo da educação e das escolas. Como no caso do etnocentrismo em que se propunham "pedagogias do olhar e da escuta" (do Outro), aqui se propõe um trabalho com a Sombra individual ("a educação do educador", de Schiller), com a Sombra coletiva (a problemática do Outro - racismos) e com a Sombra biológica (o trabalho com o corpo, porque o corpo é, ao mesmo tempo, a âncora do Imaginário e do Inconsciente e a Sombra, no universo da cultura do ocidente e das pedagogias intelectualistas e positivistas).

Em culturanálise de grupos, os trabalhos de José Carlos de Paula Carvalho no Liceu Pasteur, no Colégio Iavne e na E.E.P.S.G. João Pedro Ferraz, evidenciam a presença desse "universo da angústia" e 
a problemática da Sombra, explodindo respectivamente sob a forma de um imaginário da morte e da derrelição (abandono metafísico), imaginário da perseguição e do bode expiatório, e imaginário da corporeidade explodida. O trabalho de Icléia Rodrigues de Lima estuda, no universo de quatro escolas em Cuiabá, a presença do corpo como Sombra e os problemas que isso acarreta para a escola, pelo fato de não ser levado em conta numa “pedagogia implicativa” (Remi kbs), e, por isso, acaba explodindo como badernas, depredação, drogas, sexualidade transversal, relações perversas professoraluno etc.

O imaginário da corporeidade é de extrema importância em toda essa dinâmica do etnocentrismo e da Sombra pois, se não levado em conta, é origem de três políticas extremamente nocivas ao funcionamento de uma cultura criativa: a "peste emocional", de que nos fala WReich;a "dissidência libidinal", de que nos fala Lapassade e Lourau;e as "práticas de dejeção dos inter stícios", de que fala Roussillon. Podem ser estratégias de morte e de extermínio. Diz Dadoun (199@p.15:

aqueles que jogam as primeiras pedras, aqueles que vêem o cisco no olho do vizinho mas não vêem a trava que está no próprio olho, aqueles que têm telhado de vidro mas atiram pedras no do vizinho, aqueles que fofocam e criam rumores assassinos, aqueles que jogam a polícia e os juízes e os cães e a multidão e os psiquiatras e os educadores nas pegadas do vagabundo, do judeu, do negro, do imigrado e do marginal, e aqueles que proclamam em grandes berros místicos suas furibundas verdade s'religiosas, políticas, científicas e todos aqueles incontáveis zé-ninguéns'que seguem em co ro - de igreja, de partido ou de seita - os fuhrers', aglutinando-se e fazendo-se multid ão, esquecendo-se em sua porção de Sombra, para saborear a calúnia, criar o rumor, veicular mentira e difamação, constituir as tribos de aclamação, alimentar as fogueiras, correr para o linchamento e, de todo o coração e com toda a boa intenção, assegurar a boa administração dos asilos, das prisões e dos tampos de concentração', os salvadores do país, que querem o bem do povo, sabendo o que é melhor para ele, e a massa imensa e pretensamente silenciosa que baba jogando as últimas pedras, eis algumas das figuras da pestilência caracterial-social que WReich descreveu e contra a qual lutou até a morte como peste emocional', que acabou por matá-lo".

Esse fulcro do fascismo, que é a "couraça do caráter autoritário", na própria blão Soviética pósrevolução fez gorarem nas escolas as propostas de WReich e \&ra Schmidt. Esse fulcro espreita o discurso neoliberal no Basil e a adesão maciça à política presidencial (à eleição...). Éa "personalidade autoritária" como "couraça de caráter" da maioria dos brasileiros: apesar da "ética do jeitinho" e da desenvoltura corporal, não há "dissidência libidinal” entre os brasileiros capaz de fazer explodir a "couraça do caráter", corroborando o que WReich dizia que, "antes de Bonenhuma mudança vai acontecer em educação...". A "dissidência libidinal” consiste em, tão só pelo modo de ser e pela existência, "pro-vocar" as instituições a falarem (o que se chama "efeito analisador" em análise institucional), infelizmente e geralmente, fala de morte dos "zé-ninguéns", aparentemente imotivada, mas dotada de uma motivação extremamente profunda que se desconhece, e por isso é perigosa e faz 
perigar, como é precisamente o caso em "Sem Destino". Éa "Cavalaria do Mal" que anda pelas paragens do Basil. Mas há a "Irmandade dos Anéis"...

\section{REFERÊCIAS ĐIOGRÁFICAS}

BBDIEUP. La distinction: critique sociale du jugement. Paris: Minuit, 1979.

INGTON, C. Desenvolvimento da personalidade: símbolos e arquétipos. São Paulo: Ática, 1987. Dimensões simbólicas da personalidade. São Paulo: Ática, 1988.

DADON, R. LOccident et ses Autres. Paris: Aubier, 1980

Cent fleurs pour WReich. Paris: Payt, 1990

DE MARTINO, E. Furore, simbolo, valore. Torino: Bringhieri, 1984

DOGLAS, M. Pureza e Perigo. São Paulo: Perspectiva, s.d.

GARCEZM. C. de O. Culturanálise de um grupo de mulheres da Favela da Na Dalva/ SP. São Paulo, 1990Tese (Doutorado). Faculdade de Educação da SIP.

GOMES, I. R. de L. A escola como espaço e tempo do prazer: uma análise proxêmica. São Paulo, 1993,

Tese (Doutorado). Faculdade de Educação da BP.

JNG, C. G. Aion. Petrópolis: 女zes, 1989.

_ et alii. Le fripon divin. Genèe: Lib. Georg, 196.

LAPASSADE, G. A entrada na vida: ensaio para uma filosofia do inacabamento. Lisboa: Presença, 1970 LAPASSADE, G. et alii. Le corps interdit. Paris: ESF, 1989.

LÉSTRAES, Cl. Tristes tropiques. Paris: GE, 196

LOBIUR. A análise institucional. Petrópolis: Њzes, 1976

KAË, R. Qatro estudos sobre a fantasmática da formação e o desejo de formar. Tradução CICEFESIP-EDA, 1996

PAUA-CARXLE. J. C., RDIA, D. As raizes e complexidade das noções de educação fática e cotidiano oximorâico. Atas do MI Ciclo de Estudos do Imaginário, Centro de Estudos do Imaginário, Departamento de Antropologia, EPE, Recife, 1996

O imaginário de alunos de escolas de 1. e 2graus . Relatório Final do Projeto Integrado CNPq/FEBP:1996

REICHMN Escuta, Ė-ninguém . São Paulo: Martins Fontes, 1970

$\mathrm{O}$ assassinato de Cristo. São Paulo: Martins Fontes, s.d.

REICHME SCHMIDT, V Psicanálise e Educação. Lisboa: Presença, 1983.

RODRIGES, J. C. Tabus do corpo. Rio de Janeiro: Achiamé, 1990

TANB, M. I. J. Mundividências: estudo sócio-antropológico sobre um grupo de migrantes do Birro Planalto, Cuiabá-MT. São Paulo, 1993. Tese (Doutorado). Faculdade de Edu cação da SP,

TAGLFFF, J. La force du préjugé, le racisme et ses doubles. Paris: Gallimard, 1990

$\mathbb{Z}$ VIG, C., ABAMS, J. Ao encontro da Sombra. São Paulo: Cultrix, 1994 
DERTES

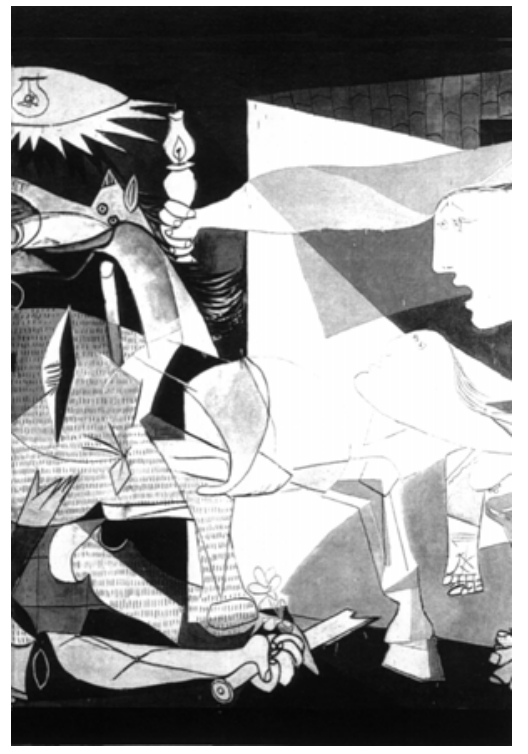

Guernica (detalhe), 1937, PICASSO,

Museo Prado, Madrid.

186 Inteface -Comunic, Saúde, Educ 1 